\title{
Phoning it in? Examining Pre-Employment Phone Interview Procedure in Higher Education
}

\author{
Paul James Antonellis (Corresponding Author) \\ Faculty \& Director of Human Resource Management Programs \\ Merrimack College, North Andover, MA \\ United States \\ Email: antonellisp@merrimack.edu \\ Danielle Flam \\ Lecturer of Management \\ Merrimack College, North Andover, MA \\ Email: flamd@merrimack.edu
}

Received: January 10, 2016 Accepted: February 12, 2016 Published: February 27, 2016

doi:10.5296/ijhrs.v6i1.8982 URL: http://dx.doi.org/10.5296/ijhrs.v6i1.8982

\begin{abstract}
In the United States, the employment screening process for hiring full-time faculty in higher education involves the vetting of curricula vitae, phone interview(s), and/or campus visits (Cardeiro, 2010; Shively, Woodward, \& Stanly, 1999). The purpose of this research was to examine the phone interview procedure at one institute of higher education, and from there, formulate a systematic phone interviewing procedure that could be put to use at this particular university.

After conducting a review of relevant literature, the researchers engaged in action research that utilized qualitative data of 10 participants who took part in the pre-interview, professional development intervention, and the post-interviews for this research project. The action research protocol involved identifying the problem to bring about a positive organizational change, selecting the needed change, implementing the proposed change, and evaluating the results of the change. Upon completion of which, three emerging themes from the collected data were determined: a) phone interview procedure and structure, $b$ ) assessment and screening procedures, c) organizational fit.
\end{abstract}

This research proves to be significant because it expands the current knowledge on the topic 
of conducting employment phone interviews in higher education for tenure track faculty. How higher educational institution conduct faculty screening is often considered a trade secrets, resulting in other institutions unwillingness to provide information on how they conducting faculty screening (Trower, 2012). By sharing this protocol with the field, places of higher learning can begin to assess and measure their own hiring procedures, and correct practices that may be flawed, inequitable, or possibly illegal.

Keywords: Employment interview, Phone screening, Higher education, Faculty, Action research

\section{Introduction to the Problem}

The employment interview process is the most widely used procedures used in the employment screening process today (Macan, 2009; Pettersen \& Durivage, 2008). The fields of psychology and sociology explored in depth the many aspects that surround the employment interviewing process (Bye, Sandal, van, Sam, Cakar, Franke, 2011; Dalgin, Bellini, 2008; Huffcutt, A. I., Culbertson, \& Weyhrauch, 2013; Tran \& Blackman, 2006). The employment screening process can be a highly structured process or it can range to an unstructured process; were the interview process has no established questions or format that the interviewer performs while screening the candidate. The unstructured interview is often the most widely used procedure when organizations decide the process they will use in screening candidates for an open position (Rudin \& Gover, 2007). The employment interview format and degree of structure can have a positive or negative impact on the selection process and the organization.

In the field of higher education in the United States, the employment screening process for hiring faculty involves the screening of curricula vitae, phone interview, and campus visits for a in person interview, or a combination of these methods (Cardeiro, 2010; Shively, Woodward, \& Stanly, 1999). Depending on the academic position, the resume screening may involve 70-100 resumes with the goal of narrowing down the pool of candidates to 10-15 candidates to offer phone interviews. The final step in the screening process may be the offering three candidates the opportunity to travel to the academic campus for a personal interview (Close, Moulard, \& Monroe, 2011). Ryan, Sacco, McFarland, and Kriska (2000) and Smither, Reilly, Millsap, Pearlman, and Stoffey (1993) suggested that candidates may self-select out of the interview process, if the candidate has a negative feeling from the interview process before being offered the position.

A number of items can negatively influence the employment interview procedure; steps need to be taken to minimize or eliminate these areas. The first step is open, honest and respectful communicate the potential areas that may have a negative impact on the employment interview process with the various stakeholders involved in the screening process; involving the human resource management department, the hiring manager for the department, labor union representatives, faculty senate, and other stakeholders in discussions to minimize or eliminate the factors (Deal \& Peterson, 2009). The goal should be to promote and support a 
transparent screening process.

Public and private agencies performing employment screening are required to follow the laws and regulations (Russo, 2009). Alder and Gilbert (2006) reported, "Adherence to legal requirements alone is not sufficient to guarantee ethical hiring" (p.450). In today's turbulent economic market and legal challenges, demands for transparency is a central issue with the employment screening procedure; the depth of research involving the employment interviewing process, agencies are held accountable for the employment screening procedures they adopt and the quality of the employee hired. The findings provided by this study will benefit those who are charged with the faculty employment phone screening procedures in higher education. In an effort to protect the sensitive information and techniques surrounding the hiring procedure at the research site, the institution will not be identified in this report; the institution will be referred to as the "research site" through this report.

\subsection{Statement of the Problem}

The problem addressed in this research is that the field site is lacking a clear and systematic process for conducting faculty employment phone interview screening procedures. The phone interview process is often conducted after the initial review of curricula vitae's at the research site. The research site is at the beginning stage of a multi-year hiring process due to two early retirement programs offered to senior faculty members and the increase in student enrollment.

The goal of this action research project is to create a systematic procedure for conducting employment phone interviews and to implement a professional development intervention. The goal of the professional development intervention is to improve the procedure and performance of the faculty members conducting the phone interview screening process during a faculty search.

\subsection{Interview Structure}

The definition of structured employment interviews has a wide range of acceptance in academic literature. For the purpose of this paper, we define a structured employment interview as an established procedure used on each employment candidate, with each candidate being asked the same questions in the same format (Chapman, \& Zweig 2005; Dipboye, Wooten, \& Halverson 2004).

Importantly, employment interviews are often conducted in an unstructured format; were the interview does not follow any standard process or standard questions of the candidate (Rudin $\&$ Gover, 2007). In the field of human resource management, it is widely held that the employment interview procedure is considered valid when the interview questions asked of candidates are the same for each interview; the assessing and scoring of individual candidates are based on job related questions for each interview conducted (Huffcutt, Culbertson, \& Weyhrauch 2013; Klehe, König, Richter, Kleinmann, \& Melchers, 2008).

The structured interview process will determine what questions will be asked of each candidate and each question will also have a prompting question as a means to gain clarification on the candidates original response to the question or if the candidate does not 
fully understand the question being asked. The structured interview questions will also have a scoring scale that the interviewer can use to assign a score of the answer provided. Going further, the structured format allows for each candidate to be asked the same set of questions and the same rating scale to ensure a level of consistency, same time limits for each interview, and same interviewer asking the questions of all candidates (Conway, Jako, \& Goodman, 1995; Levashina \& Campion, 2007). Therefore, to reduce employment screening errors, it is recommended that a structured employment interview be conducted.

\subsection{Interview Training}

The phone screening procedure is frequently used in higher education during the employment screening process. Academic literature emphasizes the need for formal telephone interviewing training; however most telephone interviewers receive little to no formal training on how to conduct phone interviews (Camp, Schulz, Vielhaber \& Wagner-March, 2011; Campion Palmer, \& Campion, 1997; Dipboye, 1992; Palmer, Campion, \& Green, 1999). Stevens (1998) reported, "Firms may influence interview processes and outcomes through their screening-recruiting priorities and interview training program" (p.84). Given the importance that the phone interview process holds in the employment screening process for faculty, the literature supports the idea of conducting phone interview training before conducting the interviews. This research focused on the creation of a systematic phone-screening procedure for hiring faculty in high education.

\subsubsection{Background and Context}

The research site does not have any formal written procedure for conducting phone interviews for tenure-track faculty. Each faculty search committee determines what procedure they will use for conducting the search. Each employment search results in different procedures being used by the search committee. Each individual school at the research site is responsible for creating and conducting their own employee screening process, without any consultation with the human resource management department. The practice of not involving the institution human resource management department goes against current research in the field of human resource management (Casper, Wayne, \& Manegold, 2013; Sinha \& Thafy, 2013). The employment search committee members rely on former search committee members providing the background on prior faculty searches.

\subsection{Assumptions and Limitations}

Krathwohl and Smith (2005) suggest that "Assumptions underlie all studies" (p.139). This research includes several assumptions. The first assumption, the researcher assumes that the research participants will provide truthful responses during the interviews and the professional development intervention. The second assumption, the professional development intervention session will provide the participants with new insight as to how employment phone interviews have been performed in the past and suggested areas of improvement; leading to a positive change in how future phone interviews will be conducted at the research site. The third assumption is that the selected instrument will adequately capture the research participants' options, perceptions and beliefs. 
One limitation with this research study was including outside higher educational institution in the project. The procedure used to screen tenure track faculty in higher education is often characterized by secrecy and the lack of a clear procedure makes conducting this type of research difficult (Trower, 2012; Roach, 2015). The limitation will be minimized by the creation of a clear set of goals and remaining focused on those goals. The intent of this action research study will be to focus on the individual research site and not seek data from other higher educational institution.

A second limitation identified is that the results from this research may not be generalized to all higher educational institutions that conduct phone interviews as part of the employment screening process. It is noted that this research is based on a small sample size at a single private faith based higher educational institution. This action research project could be expanded throughout the other schools within the institution, allowing for a larger sample size.

The third limitation to this action research project is that the participants at the institution are volunteer participants in all three requirements for the project (pre-interview, professional development intervention, and post-interview). Each search committee conducting future employment phone interviews will be allowed to accept or reject any of the recommendations of this research in conducting future searches. The tenure track faculty hiring is a primacy issue for the faculty at the research site, the human resource management department is not part of the screening procedure and the administration has a very narrow scope of involvement at the campus visit stage of the screening procedure.

\section{Literature Review}

The literature review represents a thorough review of empirical literature on the topic of employment screening procedures and the theoretical framework in support of the action research study. The literature review began with the extensive review of employment interviewing and narrowed the focus on the phone interview screening procedures, exploring the types of questions often used during the phone interview screening process, and the types of training conducted before performing employment phone screening procedures.

The review of literature is organized into 10 functional sections: (a) general interviewing process, (b) employment phone interview, (c) employment structure and unstructured interview, (d) interview questions, (e) interviewer training, (f) legal issue, (g) interviewer bias, (h) types of interview questions (behavioral, situational, knowledge), (i) organizational fit, and (j) interviewer note taking. A comprehensive reviewed of the 10 sections of empirical literature revealed three main areas that this action research will focus on are (a) nonverbal cues pertaining to the employment interview, (b) types of interview questions used in an employment interview screening process, (c) the need for professional development training for individuals performing employment screening interviews (Antonellis, 2015).

For the past 100 years, the employment interviewing process has been considered largely a static procure used during the employment selection process (Dipboye, 1997; Huffcutt, 2011; Wagner, 1949). Since the early 1900's, researchers have struggled with identifying one best 
approach for every type of employment interview (Gomes \& Neves, 2011; Van Der Vorm, 2001). Selecting and hiring the best candidate for the position will allow the organization to achieve or exceed its organizational goals; hiring the wrong person for the position may result in a negative impact for the organization and require a protracted personnel claim (Chen, Tsai, $\& \mathrm{Hu}, 2008)$. The complexity of the hiring procedure is dependent on multiple factors; type of job, organization, skill, abilities, talent management system. Batt and Colvin (2011); Hunter, Cushenbery, and Friedrich, (2012) suggested that the hiring procedure can range from a basic employment interview and immediate job offer to a more complex procedure lasting several months. Huffcutt (2011) believed that the interviewers who understood the complexities of the employment interviewing process resulted in the best position to predict how a candidate might perform in the future.

In the field of higher education, the hiring procedure for faculty can take place twelve to six months prior to the actual start date, depending on the faculty position and the institution. Reviewing of resumes remains the first step in the selection process, for narrowing down the field of candidates to a small group of candidates. Candidates are often invited to participate in a phone interview to further narrow down the pool of candidates to invite three to four candidates to campus for an in-person interview (Huffcutt, van Iddekinge, \& Roth, 2011). The goal for each step of the candidate screening process is to review and identifying the best candidates to advance to the next step in the screening process. Each step will narrow down the pool of candidates, with the final step being an offer of employment.

\subsection{Theoretical Framework}

Espoused versus theory was used in this action research project in relation to identification of the problem(s), implementing changes, and assessing the results of the change to determine if successful as it pertains to the phone interviewing procedures at the research site. Anderson, Herr, and Nihlen (1994) suggested that individuals within an organization may use a defensive route, referred to as Model I behavior to resist changes. Model I behavior can be observed in organizational settings were members tell others what they want to hear in an effort to safeguard their own self-serving actions. Argyris (1993) asserted that action research is utilized to transfer individuals within the organization from a Model I behavior style to a Model II behavior style. Model II style of behavior supports and inspires individuals to interact, engage, collaborate, and to analyze the problem(s), allowing the individuals a voice in the change resulting in a positive change environment within the organization.

\section{Methodology}

The research methodology selected for this research is action research and will utilize qualitative data. The action research protocol involves identifying the problem to bring about a positive organizational change, selecting the needed change, implementing the proposed change, and evaluating the results of the change. The objective of the action research is to determine the extent of the change utilizing Model II behavior (Argyris \& Schön, 1996). Model II behaviors promotes and allows for all of the stakeholders to have an voice in the process of identifying the problem, suggesting possible changes, and provides open, honest and respectful insight on the results of the changes to determine if the intended results have 
been achieved.

\subsection{Research Question}

The research study aim was to identify and address the need for a systematic phone interview screening procedure for faculty search committee members in higher education. The following two questions guided the study:

1. How will a professional development intervention create a systematic employment phone screening procedure for hiring tenure track faculty at the research site?

2. What are the policies, procedures, or guidelines needed to improve the employment phone screening procedure for hiring tenure track faculty at the research site?

The aim of research Question 1 is to identify how a professional development intervention will develop a systematic employment phone screening procedure for hiring tenure track faculty at the research site (Camp et al., 2011; Campion et al., 1997; Dipboye, 1992). The first step was to review the current literature on the subject of interviewing and interview procedures in higher education. At the completion of the literature review, the data collection processes began with the collection process from internal stakeholders at the research site who had prior experience conducting phone interviews at the research site to provide insight into the problem with the current procedure. The next step was to review documents provided by the research site pertaining to the phone interview procedure for tenure track faculty. Following the data analysis from the literature review, stakeholders interviews, and document reviews a professional development intervention was created including a recommendations for hiring tenure track faculty document containing pre-interview steps, interview steps, and post-interview steps. The document also contained phone interview questions perversely used by search committees at the research site along with follow up questions to allow further exploration of the area. The second bank of questions developed were questions recommended for future phone interviews and follow questions.

Research Question 2 is to measure the policies, procedures and guidelines used previously in tenure track phone interviews for tenure track faculty at the research site. The data collected and analyzed from this question will aid in the development of the creation of a systematic employment phone screening procedure for hiring tenure track faculty for the research site. Highouse (2008) suggests that employment screening committees have many options available to aid them during the screening process, however most will resist the use of a standardizes procedure for screening of candidates. The intent of Question 2 is to gain insight into the current screening procedure utilized at the research site and to help facilitate the creation of a systematic phone screening procedure that can be used by all tenure track faculty employment screenings (Huffcutt, 2010).

\subsection{Research Design}

This research project is designed to collect and analyze the data from the research participants that would aid in the creation of a systematic phone interviewing screening procedure for hiring tenure track faculty at the research site. In addition, the data will aid in the creation of a 
professional development intervention for the research participants at the research site. The research design requires three separate data collections activities that the research participants must attend to take part in this research project. The three data collection activities are:

1. Pre-interview data collection consisted of current and former faculty search committee members who were currently employed at the research site. The data provided insight into the behaviors and attitudes of the participants towards the current employment screening procedure used during the phone interview process. The key element was selecting research participants who had prior experience in performing employment screening procedures at the research site to ensure that data could be collected as to the current procedure, historical perspectives, and to collect participant's recommendations on areas to improve.

2. Post-interview collected data from research participants after the professional development intervention session. The aim was to collect data to help determine the effectiveness of the professional development intervention for faculty search committee members' behaviors and attitudes towards the phone interview process.

3. Observations will be recorded in writing during the professional development intervention session of the research participants to provide insight as to the research participants' beliefs and what changes could be made to improve the current procedure. The written documentation included brief statements, beliefs, and attitudes observed by the search participants. Each research participant received an electronic copy of the Faculty Recommendations for Phone Interviews document, the document was developed in response to the data provided from the pre-interview, research site document review, and current literature review.

\subsection{Target Population \& Size}

The target population for this research consisted of current full time faculty at the research site who had prior experience with the phone interview procedure at the research site. The full time faculty included tenure-track faculty (Assistant Professor), tenured faculty (Associate Professors and Professor), and term faculty (Assistant Professor) at the research site. A total of ten participants volunteered to participate in the research project; the ten participants are consistent with the sample size for a qualitative study (Crestwell, 2013; Denzin \& Lincoln, 2011). Participants volunteered to participate in the search project and they were required to have prior experience conducting phone interviews for tenure track faculty positions at the research site. Participants were required to take part in the pre-interview, Post-interview, and professional development intervention.

\subsection{Sampling Method}

The pre-interviews utilized qualitative data techniques to examine and evaluate how the research site conducted employment phone interviews for tenure track faculty hiring in an effort to identify possible problems, recommend improvements, and develop a list perversely used interview questions at the research site. The professional development intervention session allowed participants to see the results of the pre-interview data results and 
recommended standard of practice for conducting phone interviews from the literature review. During the professional development session participants views and perceptions were recorded (Coghlan \& Brannick, 2010). The final data collection involved the post-interview session to assess if any change had occurred with the participants pertaining to the phone interview procedure used for hiring tenure track faculty.

The research site inter-office email system was utilized to send out a message to all fulltime faculty inviting participants to take part in the research. The initial email message outlines the time commitment for participation, inclusion criteria, and research location. Attached to the initial email communication was an electronic copy of the Informed Consent Form; clarifying the research intent, time commitment, participation, protection of participants' identity, and research project withdrawal process for participants'.

\subsection{Data Collection}

The data collection involved a multi-step process for this action research project. The first collection point was the individual interviews (pre-interview) with each individual participant. The second data collection point was reviewing the documents provided by the research site that prior tenure track faculty committees used for conducting phone interviews. The data from the two points was used in developing the professional development intervention session. The following six questions were asked of the participants' during the individual interviews (pre-interviews):

1. Please describe in detail the procedure used during the employment screening process for conducting phone interviews for tenure track faculty.

2. What qualities or skills are you looking for in the candidates during the phone interview?

3. Provide an example of what you think is the best type of question to ask a candidate during the phone interview. What kind of information are you trying to extract from the question?

4. In your experience, do you take detailed notes during an interview or do you wait until the end of the interview before writing your notes? Provide examples of what you might include in your interview notes.

5. Describe in detail the strengths and weaknesses of the current procedure?

6. What suggestions, if any, do you have to improve the hiring process (Antonellis, 2015)?

The third data collection point was the literature review in an effort to further understand the issues confronting the research site. The literature review data, individual interviews data, and the document review data provided a triangulation of data for the development of the professional development intervention. The three data points provide an increase in data validity and verification.

The fourth data collection point was during the professional development intervention, 
participants' observations were recorded to better understand the participants' beliefs towards the current employment phone interview procedure at the research site and what improvements they might suggest for areas of improvement. The intent was to collect data from the participants' on areas of improvement for future employment phone interviews for tenure track faculty.

The fifth data collection point was the post-professional development intervention individual interviews with the research participants'. The data collected will be used to evaluate the professional development intervention behaviors and compare it to the pre-intervention data. The following three questions were asked in the post-intervention interviews of all participants':

1. What new insight have you gained from the professional development training that are relevant to the hiring process through phone interviews?

2. What changes, if any, do you propose to improve the current hiring process of tenured-track faculty through phone interviews?

3. What reasons, positive or negative, do you have for recommending that such a training session be taken by all interview committee members in the future?

\section{Data Analysis and Findings}

\subsection{Data Analysis}

Action research procedures were utilized in this research project based on the recommendations of Argyris, \& Schön (1989); Coghlan \& Brannick (2011), Feldman (2007); Patton (1990) for conducting qualitative research. Data was collected from two sets of individual qualitative interviews for this research. The each of the interviews was reduced to written transcriptions, representing more than 730 sentences and 74 pages of transcriptions for all the interviews; allowing for thematic coding in order to identify emerging themes.

Once the pre-interviews were conducted, transcriptions made, and data analyzed the data was used to aid in the development of the professional development intervention session. The professional development intervention was conducted, data analyzed, and the results are shown to identify how the participants felt and thought about the professional development intervention. The post-interviews were conducted, transcriptions made, data analyzed, and the results are shown to identify the results of this research project.

\subsection{Research Validity}

The goal of this research project was to establish validity, credibility, transferability, and reliability by employing multiple data points. The use of pre and post interview transcriptions provided rich data for the research project, the review of documents provided by the research site pertaining to prior employment phone interviewing procedures, and the observation protocol sheet collected during the professional development intervention. These data points provided a brief view of the current employment phone interview procedure for tenure track faculty. Every effort was taken to ensure that the data collected from each source was not 
overreliance on any one type of information collected for this project.

The external validity for this research can be generalized in the fact that the data was used to create the professional development intervention and finally the recommendations for improving the phone employment screening process at the research site. The inferences generalized from this research can be applied to a larger population or the content could be transferrable to other contexts, such as staff hiring for higher education or use in intuitions outside of the higher education field (Troche \& Donnelly, 2008). The internal and external validity for this research was considered in the planning process and was continuously assessed during the research project.

\subsubsection{Description of Participants}

The participants in this study included ten current full-time faculty members at the research site, all who had prior experience conducting phone interviews for tenure track faculty at the research site. The research participants participated in all three data collection points: pre-interview, professional development interventions, and post-interviews. The participants included tenure-track and tenured faculty (Assistant Professor, Associate Professors, and Professor).

The participants in this study included six males and four female participants. As a requirement for participation in the research project each participant had to have prior experience conducting phone interviews for tenure track faculty at the research site. A total of four participants have performed one-two phone interviews, two participants have performed two phone interviews, two participants have conducted six to nine phone interviews, and two participants performed ten or more phone interviews.

The participants in this study years of experience in higher education is broken down into the following categories, representing a mix of experience in higher education: Three of the participants had three to five years of experience, two of the participants had six to ten years of experience, and five participants had more than 21 years of experience in higher education. The minimum number of years of experience was three years and the maximum number of years of experience was thirty-five.

Participants in this study reported that they invited an average of 9.3 candidates to participate in an individual employment phone interview process for tenure-track faculty at the research site. Three participants reported that they invited four to seven candidates to participate in a phone interview, four participants reported that they invited eight to eleven candidates to participate in a phone interview, two participants reported that they invited twelve to fifteen candidates to participate in a phone interview, and one participant reported that they invited sixteen or more candidates to participate in a phone interview at the research site.

Participants represent a mix of diverse rank and experience conducting employment phone interviews in higher education for tenure-track faculty. The diverse rank and experienced allowed for a deeper understanding of how prior employment phone interviews were conducted at the research site, collecting data on what steps have proven successful in conducting phone interviews, and collecting recommendations for areas of improvement. 


\section{$\Lambda$ Macrothink}

\subsection{Findings}

Three main themes emerged from the pre-intervention interviews are: a) phone interview procedure and structure, $b$ ) assessment and screening procedures, c) organizational fit. The six pre-intervention questions asked revealed that $100 \%$ of the participants indicated that procedure (for conducting phone interviews and committee structure) was the main theme. Vetting of candidates procedures (assessment and Screening) during the phone interview process was the second merging theme representing $67 \%$ of the six pre-intervention questions. The data from the pre-intervention interviews revealed that $80 \%$ of the participants believed that the candidates possible fit with the organization and faculty was a significant assessment factor during the phone interview process.

A review of the pre-intervention interview transcriptions provided insight into the need for a written document to provide guidance for conducting phone interviews for tenure track faculty positions in the future based on the research participant responses. It was this emerging theme that provided the basis for developing a best practice guide for conducting phone interviews for tenure track faculty positions and introducing the best practice written guide during the professional development session.

The following list identifies the themes for all six questions asked during the pre-intervention interview and was used to help develop the Faculty Recommendations for Phone Interviews document. Code $1 \mathrm{G}$ represents the theme procedure. Code $2 \mathrm{G}$ represents the theme organizational fit. Code 3G represents the theme committee. Code 4G represents the theme vetting. The four themes denote the emerging themes for all of the pre-intervention interviews conducted for this research project. As shown in Table 2, self-reported change relating to the procedures utilized by participants performing phone interviews as a result of espoused theory in action.

Ninety percent of the participants reported they found the Faculty Recommendations for Phone Interviews document helpful; ten percent reported that the document was too constricting. Ninety percent of participants reported that they felt additional employment phone interviewing training was not needed for future search committees members due to the limited time that the search committee members have to commit to the entire search process. Participants reported that they felt that requiring additional training would only increase the time commitment to a process that is already very labor intensive; resulting in faculty unwieldiness to participate in future searches due to the time commitment. 


\section{Macrothink}

International Journal of Human Resource Studies

ISSN 2162-3058

2016, Vol. 6, No. 1

Table 1. Themes for Pre-Intervention Responses and Initial Coding

Question Themes for questions 1-6 regarding phone interview

$\operatorname{Code}(\mathrm{s})$

1 Code 1 A represents the theme pre-screening of candidates.

$1 \mathrm{G} 3 \mathrm{G}$

Code $2 \mathrm{~A}$ represents the theme time/schedule for interview process.

Code $3 \mathrm{~A}$ represents the theme search committee participation.

Code $4 \mathrm{~A}$ represents the theme phone interview procedure.

Code $5 \mathrm{~A}$ represents the theme phone interview questions.

Code $1 \mathrm{~B}$ represents the theme organizational/cultural fit for the candidate and the $1 \mathrm{G} 2 \mathrm{G} 4 \mathrm{G}$ organization.

Code $2 \mathrm{~B}$ represents the theme interest that the candidate has in the position.

Code $3 \mathrm{~B}$ represents the theme academic research.

Code 4B represents academic teaching.

3 Code $1 \mathrm{C}$ represents the theme organizational/cultural fit.

$1 \mathrm{G} 2 \mathrm{G} 4 \mathrm{G}$

Code $2 \mathrm{C}$ represents the theme interest that the candidate demonstrates during the phone interview process.

Code $3 \mathrm{C}$ represents the theme classroom activities.

Code $4 \mathrm{C}$ represents the theme teaching philosophy.

Code $5 \mathrm{C}$ represents the theme teaching/research/service types of questions.

$4 \quad$ Code $1 \mathrm{D}$ represents the theme memory recall.

$1 \mathrm{G} 4 \mathrm{G}$

Code $2 \mathrm{D}$ represents the theme note taking to support rankings.

Code $3 \mathrm{D}$ represents the theme note taking during the interview as a prompt.

Code 4D represents the theme key words.

Code 5D represents the theme note taking for follow up questions.

Code $6 \mathrm{D}$ represents the theme note taking during the phone interview. 


\section{Macrothink}

Table 1. Themes for Pre-Intervention Responses and Initial Coding (continued)

\begin{tabular}{llc}
\hline Question & Themes for questions 1-6 regarding phone interview & Code $(\mathrm{s})$ \\
\hline \multicolumn{3}{c}{ Code 1E represents the theme vetting process used for candidates during the phone } \\
interview process. & $1 \mathrm{G} 3 \mathrm{G} 4 \mathrm{G}$
\end{tabular}

Code $2 \mathrm{E}$ represents the theme committee members activity during the vetting process.

Code $3 \mathrm{E}$ represents the theme not using the same process for each candidate is a weakness.

Code $4 \mathrm{E}$ represents the theme the phone interview process and assessment is not transparent is a weakness.

Code 5E represents the theme that the phone interview process would not withstand a legal challenge is a weakness.

Code $1 \mathrm{~F}$ represents the theme committee commitment.

Code $3 \mathrm{~F}$ represents the theme same procedure used with each candidate and each search conducted.

Code $4 \mathrm{~F}$ represents the theme phone interview documentation.

Code $5 \mathrm{~F}$ represents the theme legal protection considerations.

Note. Code $1 \mathrm{G}$ represents the theme of procedure. Code $2 \mathrm{G}$ represents the theme of organizational fit. Code $3 \mathrm{G}$ represents the theme of committee. Code $4 \mathrm{G}$ represents the theme of vetting. The four themes represent the emerging themes for the entire collection of pre-intervention interviews.

During the post-intervention interviews, ninety percent of the participants felt that additional phone interviewing training is not needed for future tenure-track faculty conducting an employment search at the research site. Nine participants $(90 \%)$ felt that the Faculty Recommendations for Phone Interviews document used during the professional development interventions was helpful, while $10 \%$ of the participants felt the document was too structured. The Faculty Recommendations for Phone Interviews document was developed based on the data from the pre-intervention interviews with the participants, current literature, and the review of documents provided by the research site pertaining to prior phone interviews. Table 2 below summarizes participants' responses pertaining to a change in behavior and/or attitudes pertaining to the phone interview procedure for tenure track faculty at the research site. The comments listed in Table 2 have minimal edits in an effort to retain verbatim exactness for the quotes provided by each participant in the research project. 


\section{Macrothink}

International Journal of Human Resource Studies

ISSN 2162-3058

2016, Vol. 6, No. 1

Table 1. Self-Reported Change in Telephone Interview Process as a Result of Espoused Theory in Action

\begin{tabular}{l} 
Part. $\quad$ Understanding pre-intervention \\
\hline P1 \\
So there are no formal procedures, The biggest insight that I gained by the training was that you \\
what my committees did was we need to be prepared. I guess I did not realize how much \\
got together as a committee and effort one needs to put into preparing for a successful \\
developed a couple of, I guess search. Preparation is critical for it to be successful. So \\
questions, maybe more broad areas getting the right people on the committee is critical and \\
that we wanted to talk to the making sure they understand the level of commitment is for \\
candidates about, when we did the the process to be successful.
\end{tabular}
phone screenings.

Definitely recommend that all search committee members attend the training or even a bridged program of it, you know before any search starts to ensure that we are all receiving the same information on how to conduct phone interviews. What the training did was to get me thinking of this as a process, you need to prepare for the interview.

P2

So what we found, with trial and I feel that the single most important point that was presented error; we became better, the more during the training session and the document is that we now we did the more effective we have a document that will provide each search committee became in the process. So...it was with the needed guidance to conduct an effective phone a little ad hock in the beginning interview. Even the smallest improvement can be helpful in presenting ourselves in a professional business manner.

I have to be honest, I do not think that others would be willing to sit down and attend a professional development session, most think they know how to conduct an interview. The sad part, they are wrong, many could use some training on how to conduct a professional interview.

P3 Very arbitrary process. But I think the importance is having some structure and sometimes, I feel like something agreement with the interview process for the committee. I clicked. I don't know how to now know what others are expecting of me as a search describe it. committee, so I can understand my situation better. So this document will not only be helpful for recruiting future employee but it will also help current employees better understand what is expected of them.

The document allows people to read when they have time; I don't think committee members will want to sit in on a training session.

They want some guidance and this document provides all members with the best options. 


\section{Macrothink}

International Journal of Human Resource Studies

ISSN 2162-3058

2016, Vol. 6, No. 1

Table 2. Self-Reported Change in Telephone Interview Process as a Result of Espoused Theory in Action (continued)

\begin{tabular}{|c|c|}
\hline Part. & Understanding post-intervention \\
\hline P4 & $\begin{array}{l}\text { I think that the current process is I think that the document you provided during the faculty } \\
\text { lacking any level of formality meeting provides a very detailed overview of the phone } \\
\text { when I compare it to what other interview process that search committees should consider } \\
\text { search committees are currently when conducting employment searches. } \\
\text { doing. } \\
\text { This is not to say that I don't think that interview training is } \\
\text { needed, I do think it's needed, I just don't think that people } \\
\text { would willingly participate. }\end{array}$ \\
\hline P5 & $\begin{array}{l}\text { We need something to use as a I had not thought of this in this much details. But now that I } \\
\text { guide, in } 2013 \text { I asked for help and look at it you make some great points. You point out what } \\
\text { there was nothing available. So we we need to check before during and after the phone } \\
\text { should have a formalize thing, interview. So I think we can utilize this as a tool for the } \\
\text { right. } \\
\text { search committee as a starting point. I think your document } \\
\text { is going to be helpful to the new search committee and we } \\
\text { all now know what the others are doing. } \\
\text { I think the training is great and the document is helpful, but } \\
\text { again my point is that everyone is busy and I might not read } \\
\text { the lengthy document or attend a training session, but } \\
\text { because I am going to be in a search I will read the } \\
\text { document because I am interested. But others may not have } \\
\text { the time for training. }\end{array}$ \\
\hline
\end{tabular}

P6 In all the ones I have participated So as long as that is the general purview, and you are in, no formal preparation for the outlining what we have done in the past and what has phone interview process. After worked in the past, I think you have created a useful everybody has asked their document. I think that once you create a central document questions, the most important that everyone has to use the same format for every single questions for them, then it was interviews, forget about it it's not gonna work.

kind of a free-for-all.

I do not feel that there is any additional training needed, if at this point in your career you do not know how to conduct a phone interview then there is something wrong. You have provided us with a document that outlines the key points.

P7 I would have to say, the first Others have the same frustration as I do while conducting a search I felt like the committee search, which is comforting.

was on its own and not being

offered much in the way of guidance how to conduct the search process, the next time we refined our process and we got better. 


\title{
Macrothink
}

International Journal of Human Resource Studies

ISSN 2162-3058

2016, Vol. 6, No. 1

Table 2. Self-Reported Change in Telephone Interview Process as a Result of Espoused Theory in Action (continued)

\begin{tabular}{l} 
Part. Understanding pre-intervention \\
\hline P8 I think the current process is I really like that this is a guidance tool and that we are not \\
working and I am not aware of any held totally to every single step and we as a committee can \\
other process that would work any select what works best for us at that time. I think we as a \\
better. Maybe if you show me committee followed many of the recommendations listed, so \\
another option and I could say that I am not going to bring anything major back to my next \\
might work, but for right now, the committee. This document reinforces that we have been \\
process seems to work. \\
$\begin{array}{l}\text { doing things the correct way. } \\
\text { document to start a new search. I don't think we need any } \\
\text { training, our time is very tight and that would require more } \\
\text { time commitment to the process, this document allows us to } \\
\text { read it and reminds us what we should be doing. }\end{array}$
\end{tabular}

P9 I told you, length of time and prep I think one thing that became clear is that we need a work, not on our side, but on the systematic approach to conducting phone interviews that is candidates' side.

\begin{abstract}
reparable and will serve as a model for us. I think the things we did in the past is consistent with the recommendations for what is a good overall process. The methodology that is used in the document is clear and it allows the committee to adopt its own style.

I don't think that training is required; I think that the recommendation template is a great tool to use.
\end{abstract}

P10 This is hard . . .because there are a This is too structured, absolutely not. Each interview is a couple of different procedures little different depending on whom you are interviewing; used, especially over time, I am this structure rubs me the wrong way. I am looking at this going to speak of the more resent from my point of view with years of experience hiring hiring procedures used. The people and I am sure the new faculty are looking at this and advantage of the phone interview, saying this is wonderful.

right now is that it is not overly

structured.

At this point, I do not need any interviewing training, I have years of experience.

As reported in Table 1 pre-intervention interview themes emerging are: (a) phone interview procedure and structure, (b) assessment and screening procedure, and (c) organizational/cultural fit. As reported in Table 2 post-intervention interview themes emerging are: (a) procedure, (b) organizational fit, (c) committee, and (d) vetting process. 


\section{Discussion and Conclusion}

\subsection{Quantitative Findings and Relation to the Literature}

A total of 10 participants took part in the pre-interview, professional development intervention, and the post-interviews for this research project. The participants reported that $40 \%$ of the participants invited eight to 11 candidates to participate in the phone interview, $30 \%$ of the participants reported inviting four to seven candidates to participate in the phone interview process. It may be assumed that the number of candidates selected to participate in the phone interview is influenced by the pool of candidates, time commitment of committee members, and the pre-employment screening procedure (CV review, brief in person meeting at national conferences) allowing the top candidates to be invited to participate in the phone interview. During the qualitative data collection process, $20 \%$ of the participants reported that they skipped the phone interview screening step because the committee felt that the top candidates had been identified by the brief in person interviews at a national conference and the review of CV along with a small applicant pool.

\subsection{Qualitative Findings and Relation to the Literature}

Research participant's post-intervention interviews data revealed $90 \%$ believed that future research committee members did not require any additional phone interview training with the common theme being committee overcommitted schedules and the resistance to increasing additional time commitment to the entire vetting process. Based on the post-intervention data that $90 \%$ of participants felt that no additional training is needed is aligned with the literature that a majority of organizations do not provide interviewing training. The post-intervention interviews further revealed that $90 \%$ of the participants reported that they found the Faculty Recommendations for Phone Interviews document helpful. The $90 \%$ acceptance rate by the participants is aligned with the Model II behaviors and espoused theory (Argyris \& Schön, 1989; Stringer, 2007), which supports the concept of seeking stakeholders' input on an issue, providing a positive work environment for the stakeholders that they have a voice, and using the input to bring about positive change in the tenure track phone interviewing process.

Emerging themes from the pre-intervention interviews as shown in Table 1 revealed that the participants had a concern about the current phone interview procedure currently in use at the research site. Participants' interviews statements revealed that they felt there is a lack of standardization in how phone interviews are performed at the research site and lack of established procedures/documentation for how phone interviews should be conducted. Participants' commented on how in prior vetting procedures seemed like a trial and error process that they could learn from for conducting the next vetting process. The data collected in the pre-intervention is aligned with the current literature Barrick et al., 2009; Chapman \& Zweig, 2005; and Levashina et al., 2014 that organizations need to conduct structured employment interviews to include as questions asked, sophistication, consistency, and standardization.

The Faculty Recommendations for Phone Interviews document developed with the data from the pre-intervention interviews, review of documents at the research site, and the literature 
review; will now allow the members of the organization at the research a central location for documenting how a phone interview should be conducted. Data collected during the pre-intervention revealed that $100 \%$ of the participants wanted to see some written guidelines or a procedure to follow when conducting phone interviews. The document is a culmination of best practices identified by the participants; the document will allow future search committee members a central location to review the recommended procedure for conducting phone interviews. The Faculty Recommendation for Phone Interviews document was shared with all faculty, administration, and staff at the research site. The professional intervention session with participants, allowed all the participants an opportunity to review the recommendations and to gain a deeper understanding of what other search committees have done in prior searches and to review recommendations for improvement. Participants' reported in the post-intervention that they now have a clear understanding as to what is expected of them as a search committee member now. The post-intervention interviews revealed that $90 \%$ of the participants feel that the document was helpful, a $10 \%$ reduction from the pre-intervention data that $100 \%$ of participants wanted to see a written guideline or procedure. These findings are consistent with the current body of literature on the topic of employment interviewing training; Camp et al. (2011), Campion et al. (1997), and Chapman and Zweig (2005) contended interview training on content, process, and evaluation is needed for those conducting interviews and little to no organizations conduct training on the topic of employment interviewing.

The pre-intervention data revealed that $70 \%$ of the participants' indicated that they are concerned with organization fit and culture fit during the phone interview process. The findings from the pre-intervention align with the current literature on organization fit during the employment vetting process (Chinomona, Dhurup, \& Chinomona, 2013; Deprez-Sims \& Morris, 2010; Gomes \& Neves, 2011; Huffcutt, Conway, Roth, \& Stone, 2001). It is important to note that because the assessments used are subjective (and often may not withstand a legal challenge in the court of law), vetting and assessing the candidates organizational fit becomes particularly challenging. Kristof (1996) and Kristof-Brown (2000) argued that the vetting process should assess the candidate on content knowledge, skills, and abilities of interest to the organizational current need. The goal is to show that the vetting process is reliable and valid based on knowledge, skills, and/or ability. Determining that a candidate is just not a good fit for the organization may not withstand a legal change and you run the risk of possibly violating the candidates' right.

\subsection{Limitations and future research}

This new research will expand the current research and knowledge on the topic of conducting employment phone interviews in higher education for tenure track faculty. The topic of how higher educational institution conduct faculty screening is often considered a trade secrete resulting in other institutions unwillingness to provide information on how they conducting faculty screening (Trower, 2012). Therefore, this research project was focused on the internal working of one higher educational institution. The fact that this research was conducted at one intuition is the first limitation. 


\section{$\triangle$ Macrothink}

International Journal of Human Resource Studies ISSN 2162-3058

The second limitation is that the results cannot be expected to apply to all higher educational intuitions given that the research site is a small private faith based intuition. The third limitation was the small sample size; it is acceptable in qualitative research to have a smaller sample size compared to quantitative research (Creswell, 2013). The qualitative questions in this research project have been refined to collect meaningful data in an effort to answer the research questions; resulting in a smaller sample size (Patton, 1990). The action research plan was designed to allow for a smaller sample size (Charmaz, 2006). The ten participants provided saturation form the pool of eighteen individuals who met the research criteria established in the data collection criteria.

The results of this research may not be generalized to all higher educational intuitions or to organizations outside of the field of higher education. In the field of higher education it may be common to begin the employment screening process and job offer/acceptance 8-10 months prior to the start day of employment. The research was confined to a private faith based four-year college. It is recommended that this research study be replicated college wide at the research site and not just a sample from the business school and/or that the research be applied to other higher educational intuitions to gain a deeper understanding of the employment phone interview process. It is further recommended that the research be expanded to several higher educational intuitions to allow for a greater sampling. However, the hiring procedure in higher education is often viewed as a trade secret and that intuitions or participant's may be unwilling to share information (Trower, 2012).

\section{References}

Alder, S. G., \& Gilbert, J. (2006). Achieving ethics and fairness in hiring: Going beyond the law. Journal of Business Ethics, 68(1), 449-464.

Anderson, G. L., Herr, K., \& Nihlen, A. S. (1994). Studying your own school: An educator's guide to qualitative practitioner research. Thousand Oaks, CA: Corwin Press.

Antonellis, P. J., Jr. (2015). Creation of systematic employment phone screening procedure for hiring tenure track faculty: An action research study (Order No. 3732454). Available from ProQuest Dissertations \& Theses Full Text. (1734891808).

Argyris, C. (1993). On organizational learning. Malden, MA: Blackwell.

Argyris, C., \& Schön, D. A. (1989). Participatory action research and action science compared. American Behavioral Scientist, 32, 612-623. http://dx.doi.org/10.1177/

0002764289032005008

Argyris, C., \& Schön, D. (1996). Organizational learning II: Theory, method and practice. Reading, PA: Addison-Wesley.

Barrick, M. R., Shaffer, J. A., \& DeGrassi, S. W. (2009). What you see may not be what you get: Relationships among self-presentation tactics and ratings of interview and job performance. Journal of Applied Psychology, 94, 1394-1411. 
http://dx.doi.org/10.1037/a0016532

Batt, R. J., \& Colvin, A. J. S. (2011). An employment systems approach to turnover: Human resources practices, quit, dismissals, and performance. Academy of Management Journal, 54, 695-717. http://dx.doi.org/10.5465/

AMJ.2011.64869448

Bye, H. H., Sandal, G. M., van, D.V., Sam, D.L., Cakar, N.D. \& Franke, G. H. (2011). Personal values and intended self-presentation during job interviews: Cross-culture comparison. Applied Psychology: An International Review, 60(1), 160-182.

Camp, R. R., Schulz, E., Vielhaber, M. E., \& Wagner-Marsh, F. (2011). Human resource professionals' perceptions of interviewer training. Journal of Managerial Issues, 23, 250-268. Retrieved from http://www.pittstate.edu/department/economics/ journal-of-managerial-issues/

Campion, M. A., Palmer, D. K., \& Campion, J. E. (1997). A review of structure in the selection interview. Personnel Psychology, 50, 655-702. http://dx.doi.org/ 10.1111/j.1744-6570.1997.tb00709.x

Casper, W. J., Wayne, J. H., \& Manegold, J. G. (2013). Who will we recruit? Targeting deepand surface-level diversity with human resource aolicy advertising. Human Resource Management, 52, 311-332. http://dx.doi.org/10.1002/hrm.21530

Chapman, D. S., \& Zweig, D. I. (2005). Developing a nomological network for interview structure: Antecedents and consequences of the structured selection interview. Personnel Psychology, 58(3), 673-702.

Charmaz, K. (2006). Constructing grounded theory: A practical guide through qualitative analysis. Thousand Oaks, CA: Sage.

Chen, Y.-C., Tsai, W.-C., \& Hu, C. (2008). The influence of interviewer-related and situational factors on interviewer reactions to high structured job interviews. International Journal of Human Resource Management, 19, 1056-1071. http://dx.doi.org/10.1080/09585190802051345

Chinomona, R., Dhurup, M., \& Chinomona, E. (2013). Does employee perceptions of fit to job, fit to organization and fit to organization and fit to community influence job performance? The case of Zimbabwe's manufacturing sector. SA Journal of Human Resource Management, 11, Art. No. 475. http://dx.doi.org/10.4102/

sajhrm.v11i1.475.

Close, A. G., Moulard, J. G., \& Monroe, K. B. (2011). Establishing human brands: Determinants of placement success for first faculty positions in marketing. Journal of the Academy of Marketing Science, 39, 922-941. http://dx.doi.org/10.1007/s11747-010-0221-6

Coghlan, D., \& Brannick, T. (2010). Doing action research in your own organization (3rd ed.). Thousand Oaks, CA: Sage. 


\section{Macrothink}

International Journal of Human Resource Studies

ISSN 2162-3058 2016, Vol. 6, No. 1

Conway, J. M., Jako, R. A., \& Goodman, D. F. (1995). A meta-analysis of interrater and internal consistency reliability of selection interviews. Journal of Applied Psychology, 80, 565-579. http://dx.doi.org/10.1037/0021-9010.80.5.565

Cordeiro, W.P. (2010). A business school's unique hiring process. Business Education Innovation Journal, 2(1), Art. No. 7. Retrieved from http://www.beijournal.com/

Creswell, J. W. (2013). Research design: Qualitative, quantitative, and mixed methods approaches (4th ed.). Thousand Oaks, CA: Sage.

Dalgin, R. S., \& Bellini, J. (2008). Invisible disability disclosure in an employment interview: Impact on employers' hiring decisions and views of employability. Rehabilitation Counseling Bulletin, 52(1), 6-15.

Deal, T., \& Peterson, K. (2009). Sharping school culture: Pitfalls, paradoxes, \& promises. $2^{\text {nd }}$ Ed. San Francisco, CA: Jossey-Bass

Denzin, N. K., \& Lincoln,Y. S.(Eds.). (2011). The Sage handbook of qualitative research (4th ed.). Thousand Oaks, CA: Sage.

Deprez-Sims, A.-S., \& Morris, S. B. (2010). Accents in the workplace: Their effects during a job interview. International Journal of Psychology, 45, 417-426. http://dx.doi.org/10.1080/00207594.2010.499950

Dipboye, R. L. (1992). Selection interviews: Process perspectives. Cincinnati, OH: South-Western.

Dipboye, R. L. (1997). Structured selection interviews: Why do they work? Why are they underutilized. In N. Anderson \& P. Herriot (Eds.), International handbook of selection and assessment (Vol. 2, pp. 455-473). Hoboken, NJ: Wiley.

Dipboye, R. L., Wooten, K., \& Halverson, S. K. (2004). Behavior and situational interview. J. C. Thomas (Ed.), Comprehensive Handbook of Psychological Assessment, 4, 297-316. Hoboken, NJ: Wiley \& Son

Feldman, A. (2007). Validity and quality in action research. Educational Action Research, 15, 21-32. http://dx.doi.org/10.1080/09650790601150766

Gomes, D., \& Neves, J. (2011). Organizational attractiveness and prospective applicants' intentions to apply. Personnel Review, 40, 684-699. http://dx.doi.org/10.1108/ 00483481111169634

Herr, K., \& Anderson, G. L. (2005). The action research dissertation: A guide for students and faculty. Thousand Oaks, CA: Sage.

Huffcutt, A. I. (2010). From science to practice: Seven principles for conducting employment interviews. Applied HRM Research, 12, 121-136. Retrieved from http://www.xavier.edu/appliedhrmresearch/issues.html

Huffcutt, A. I. (2011). An empirical review of the employment interview construct literature. 
International Journal of Selection and Assessment, 19, 62-81. http://dx.doi.org/10.1111/j.1468-2389.2010.00535.x

Huffcutt, A. I., Conway, J. M., Roth, P. L., \& Stone, N. J. (2001). Identification and meta-analytic assessment of psychological constructs measured in employment interviews. Journal of Applied Psychology, 86, 897-913. http://dx.doi.org/ 10.1037/0021-9010.86.5.897

Huffcutt, A. I., Culbertson, S. S., \& Weyhrauch, W. S. (2013). Employment interview reliability: New met-analytic estimates by structure and format. International Journal of Selection and Assessment, 21(3), 264-276.

Huffcutt, A. I., Van Iddekinge, C. H., \& Roth, P. L. (2011). Understanding applicant behaviors in employment interviews: A theoretical model of interviewee performance. Human Resource Management Review, 21, 353-367. http://dx.doi.org/10.1016/j.hrmr.2011.05.003

Hunter, S. T., Cushenbery, L., \& Friedrich, T. (2012). Hiring an innovative workforce: A necessary yet uniquely challenging endeavor. Human Resource Management Review, 22, 303-322. http://dx.doi.org/10.1016/j.hrmr.2012.01.001

Klehe, U., König, C. J., Richter, G. M., Kleinmann, M., \& Melchers, K. G., (2008). Transparency in structured interviews: Consequences for construct and criterion-related validity. Humna Performance, 21(2), 107.

Krathwohl, D. R., \& Smith, N. L. (2005). How to prepare a dissertation proposal: Suggestions for students in education and the social and behavioral sciences. Syracuse, NY: Syracuse University Press.

Levashina, J., \& Campion, M. A. (2007). Measuring faking in the employment interview: development and validation of an interview faking behavior scale. Journal of Applied Psychology, 92, 1638-1656. http://dx.doi.org/10.1037/0021-9010.92.6.1638

Levashina, J., Hartwell, C. J., Morgeson, F. P., \& Campion, M. A. (2014). The structured employment interview: Narrative and quantitative review of the research literature. Personnel Psychology, 67, 241-293. http://dx.doi.org/10.1111/

peps. 12052

Macan, T. (2009). The employment interview: A review of current studies and direction for future research. Human Resource Management Review. 19(3), 203-218

Palmer, D. K., Campion, M. A., \& Green, P. C. (1999). Interviewing training for both applicant and interviewer. In R. W. Eder \& M. M. Harris (Eds.), Employment interview handbook (pp. 337-351). Thousand Oaks, CA: Sage.

Patton, M. Q. (1990). Qualitative evaluation and research methods (2nd ed.). Newbury Park, CA: Sage.

Pettersen, N., \& Durivage, A. (2008). Structured Interview: Enhancing staffing selection. 
Presses de l’Université du Québec

Posthuma, R. A., Morgeson, F. P., \& Campion, M. A. (2002). Beyond employment interview validity: A comprehensive narrative review of recent research and trends over time. Personnel Psychology, 55, 1-81. http://dx.doi.org/10.1111/ j.1744-6570.2002.tb00103.x

Roach, J. C. (2015). Search Committees: A Comprehensive Guide to Successful Faculty, Staff, and Administrative Searches. Theological Librarianship: An Online Journal of the American Theological Library Association, 8(1), 87-88.

Rudin, J. P., \& Gover, K. L. (2007). Alternative employment practices: A call to arms. Labor Law Journal, 58(1), 39-46.

Russo, C. J., 2009). The law and hiring pratices in faith-based schools. Journal of Research on Christian Education, 18(3), 256-271.

Ryan, A. M., Sacco, J. M., McFarland, L. A., \& Kriska, S. D. (2000). Applicant self-selection: Correlates of withdrawal from a multiple hurdle process. Journal of Applied Psychology, 85, 163-179. http://dx.doi.org/10.1037/0021-9010.85.2.163

Shively, G., Woodward, R., \& Stanley, D. (1999). Strategy and etiquette for graduate students entering the academic job market. Review of Agriculture Economics, 21, 513-526. http://dx.doi.org/10.2307/1349895

Simola, S. K., Taggar, S., \& Smith, G. W. (2007). The employment selection interview: Disparity among research-based recommendations, current practices and what matters to human rights tribunals. Canadian Journal of Administrative Sciences, 24, 30-44. http://dx.doi.org/10.1002/cjas.4

Sinha, V., \& Thafy, P. (2013). A review on changing trend of recruitment practice to enhance the quality of hiring in global organizations. Management: Journal of Contemporary Management Issues, 18(2), 141-156. Retrieved from http://hrcak.srce.hr/management?lang=en

Smither, J. W., Reilly, R. R., Millsap, R. E., Pearlman, K., \& Stoffey, R. W. (1993). Applicant reactions to selection procedures. Personnel Psychology, 46, 49-76. http://dx.doi.org/10.1111/j.1744-6570.1993.tb00867.x

Snell, S., \& Bohlander, G. (2012). Managing human resources (16th ed.). Mason, OH: Cengage.

Tran, T., \& Blackman, M.C. (2006). The dynamics and validity of the group selection interview. The Journal of Social Psychology, 146(2), 183-201.

Trochim, W. M. K., \& Donnelly, J. P. (2008). The research methods knowledge base (3rd ed.). Mason, $\mathrm{OH}$ : Cengage.

Trower, C. A. (2012). Success on the tenure track: Five keys to faculty job satisfaction. JHU Press. 


\section{Macrothink}

International Journal of Human Resource Studies

ISSN 2162-3058 2016, Vol. 6, No. 1

Van Der Vorm, P. T. (2001). The well-tempered search: Hiring faculty and administration for mission. Academe, 87(3), 34-36. http://dx.doi.org/10.2307/40252017

Wagner, R. (1949). The employment interview: A critical summary. Personnel Psychology, 2, 17-46. http://dx.doi.org/10.1111/j.1744-6570.1949.tb01669. 